\title{
Synthesis of Green Diesel From Waste Cooking Oil Through Hydrodeoxygenation Technology With $\mathrm{NiMo} / \gamma-\mathrm{Al}_{2} \mathrm{O}_{3}$ Catalysts
}

\author{
Heri Heriyanto $^{\text {**) }}$, Sumbogo Murti, SD ${ }^{2}$, Septina Is Heriyanti ${ }^{2}$, Inayatu Sholehah ${ }^{l}$, Ayi Rahmawati ${ }^{l}$ \\ ${ }^{1}$ Chemical Engineering Departement, Sultan Ageng Tirtayasa University, Cilegon, Indonesia, J1. Jendral Sudirman km. 03 Cilegon \\ 42435 \\ ${ }^{2}$ Center of Technology Energy Resources and Chemical Industri, Agency for the Assessment and Application of Technology (BPPT), \\ Gedung Energi 625 Klaster V, Kawasan PUSPIPTEK, Tangerang Selatan 15314
}

\begin{abstract}
Hydrodeoxygenation (HDO) of waste cooking oil (WCO) and trapped grease over sulfide catalysts was examined to produce high quality transportation fuel from low-grade resources. The hydrodeoxygenation of waste cooking oils was carried out in a high pressure of 30 and 60 bar and high temperature of $300-400{ }^{\circ} \mathrm{C}$ in a batch reactor autoclave. $\mathrm{NiMo} / \mathrm{\gamma}-\mathrm{Al}_{2} \mathrm{O}_{3}$ catalyst was prepared and for the first time tested in hydroprocessing of waste cooking oil. The content of $\mathrm{NiMo} / \gamma-\mathrm{Al}_{2} \mathrm{O}_{3}$ in each catalyst was about WCO $5 \mathrm{wt} \%$. A maximum of $77,97 \%$ green diesel yield was achieved at nearly complete conversion of waste cooking oil using $\mathrm{NiMo} / \mathrm{\gamma}-$ $\mathrm{Al} 2 \mathrm{O} 3$ at temperature of $400^{\circ} \mathrm{C}$, pressure 60 bar and 4 hours of reaction time. The oxygen content was decreased from $14,25 \mathrm{wt} \%$ to $13,35 \mathrm{wt} . \%$, at temperature of $400^{\circ} \mathrm{C}$, pressure of 30 bar and 1 hour of reaction time. The Hydrodeoxygenation process was much influenced by temperature, pressure, and time.
\end{abstract}

\section{Introduction}

Today energy needs continue to rise but inversely proportional to energy substitutes such as petroleum, natural gas that can not be optimized. The amount of available energy sources currently is sourced from fossil fuels accounted for $94 \%$ of the national energy mix mix, comprising $47 \%$ of petroleum, $26 \%$ coal and $21 \%$ natural gas [1]. With an economic growth of 6.3 to 6.8 per year, energy demand is projected to grow around $6 \%$ per year until 2014. Fuel oil will continue to be prefered in the final energy demand, because in addition to the fact that fuel-based technologies are more efficient, fuel prices can still continue to compete if compared to other fuels such as coal and natural gas. More over, fuel oil still dominates the use of final energy, especially in the transportation sector, because the use of fuel more practical and efficient and can not be replaced by other fuels.

Considering Indonesia is the largest palm oil producer in the world with oil palm production in 2014 reaching 33 million tons so that the potential of cooking oil produced is quite large [2]. In 2007 used cooking oil (MGB) from various sources as much as 3.9 tons has not been fully utilized. This gives a huge opportunity to make Indonesia as a country that has a strong energy resistance by processing it into greendiesel with hydrodeoxygenation method, in addition to producing high fuel quality compared to biodiesel and petrodiesel, also environmentally friendly [3].

\section{Literature Review}

\subsection{Waste Cooking Oil}

\footnotetext{
Corresponding author: herfais@yahoo.com
}

Waste cooking oil is waste oil that can be made from various types of cooking oil such as corn oil, vegetable oil, samin oil and so on which when viewed from the chemical composition of the compounds are carcinogenic. In addition to the environmentally destructive wastes the chemical content formed can be harmful to human health. The first sign of cooking oil damage is the formation of acrolein in cooking oil. This acrolein causes itching in the throat when eating fried foods using cooking oil repeatedly. Acreolyn is formed from the hydration of glycerol that forms an unsaturated aldehyde.

\subsection{Green Diesel}

Green diesel is a straight-chain hydrocarbon fraction similar to that produced by the hydrogenation of triglycerides from vegetable oils [4]. The injection of hydrogen with the support of a bimetallic catalyst for the hydrotreating reaction of the triglyceride compound is capable of breaking the ester or carboxylic group bond of the glycerol group $[5,6]$. Then followed the breaking of carboxylic groups from the existing fatty acid bonds as well as the saturation reaction of the double chain carbon bonds into straight chain hydrocarbon compounds [7, 8, 9].

\subsection{Hydrogenation and Hydrodeoxygenation}

Hydrogenation technology or Hydotreatment is a branch of hydroprocessing such as catalytic reactions using hydrogen to eliminate the atoms heterogeneous (heteroatoms) such as sulfur, 
nitrogen, and oxygen, each of which is contained in the compound hydrogen sulfide $\left(\mathrm{H}_{2} \mathrm{~S}\right)$, ammonia $\left(\mathrm{NH}_{3}\right)$ and water $\left(\mathrm{H}_{2} \mathrm{O}\right)$ in a process feedstock [10, 11]. Hydrogenation process usually followed by hidrodeoxygenation reaction (HDO), decarboxylation (DCO), and decarbonylation (DCN) or combination of them [11].

Hydrodeoxygenation (HDO) is a process for eliminating oxygen hydrogenolysis of a material by cutting the carbon-oxygen bond using hydrogen gas $[12,13]$. The content of oxygen in organic compounds has a very important role in estimating the characteristics of the fuel to be generated. Oxygen levels in vegetable oils that can reach more than $50 \%$ by weight, have an impact on the low calorific value, low thermal stability, corrosive, can not be mixed with fossil fuels and the increasing tendency towards polymerization reaction [14].
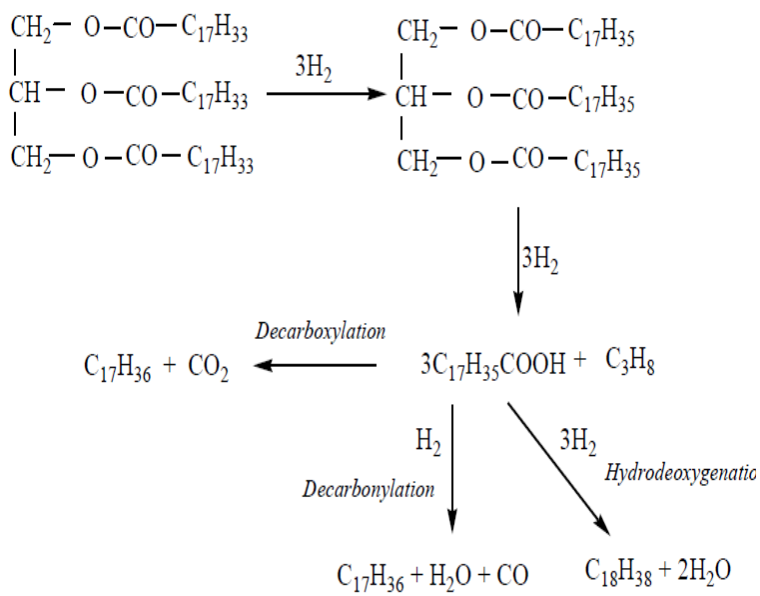

WCO $200 \mathrm{~g}$ Catalyst $10 \mathrm{~g}$ Sulfur powder $3 \mathrm{~g}$

Fig. 1. Reaction pathway of hydrotreatment

\section{Methodology}

The procedure in this study was including 10 grams of $\mathrm{NiMo} / \gamma-\mathrm{Al}_{2} \mathrm{O}_{3}$ catalyst passed 200 mesh, 3 grams of sulfur powder and 200 grams of waste cooking oil into the autoclave reactor. Then HDO processes were varied on time, temperature, pressure, and number of reaction stage with rotation speed of $800 \mathrm{rpm}$. After the HDO process was finished, the product was filtered off and separated between liquid and gas for analysis step. However, in the 2-stage, after the first stage was finished, gas in the reactor was replace by fresh hydrogen, then the reaction was continuoued in the second stage with the same pressure and time variations but with different temperatures. After the reaction process was completed, product gas was analyzed using GC-TCD Shimadzu GC-2014. The liquid product was separated from solid material by filtering. Liquid product was analized using GC-FID. More over the physical and chemical properties of liquid product was also tobe analyzed in accordance to ASTM Standard such as viscosity, flash point and elemental analysis.The operating conditions of each experiment were followed below:

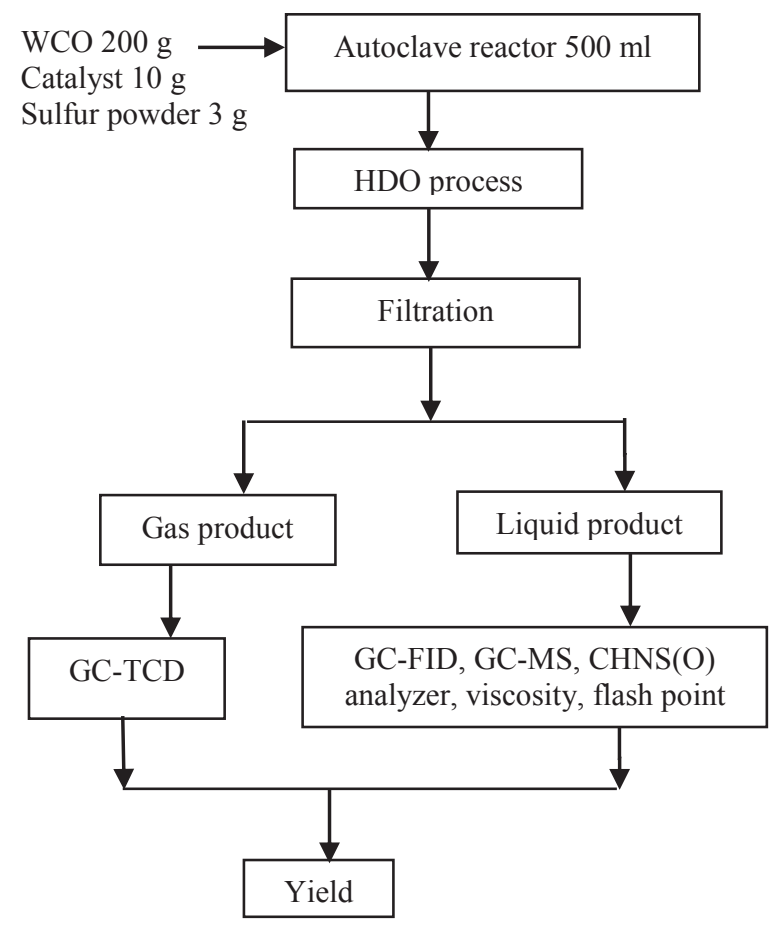

(a)

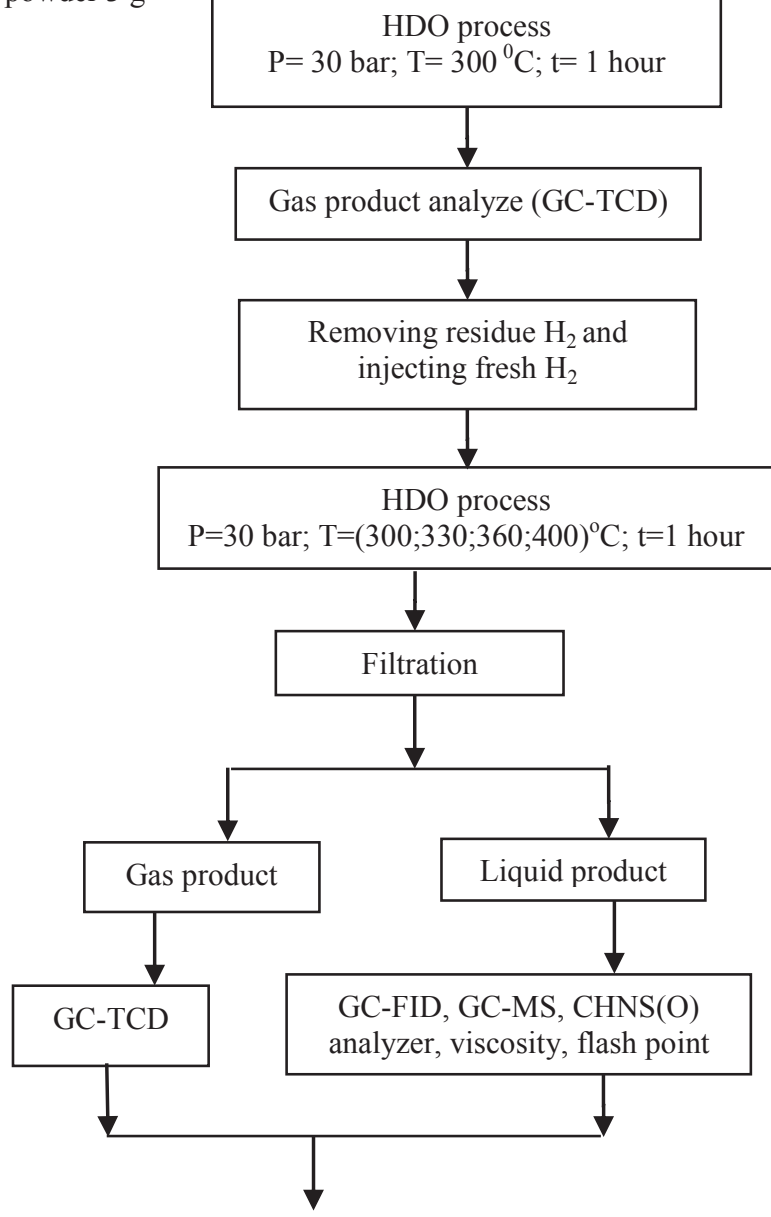




\section{Yield}

(b)

Fig. 2. Green Diesel Synthesis Scheme (a) Single reaction (b) Two steps reaction

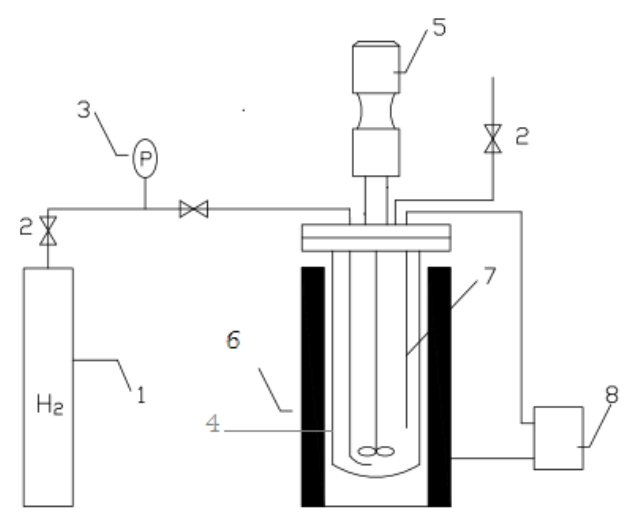

1-steel bottle; 2-valve; 3-pressure gauge; 4-reaktor;5-electrical machine; 6-jacket; 7-thermocouple; 8-controller

Fig. 3. Schematic and Equipments of Experimental

Table 1. Operating Conditions

\begin{tabular}{|c|c|c|c|c|c|c|c|}
\hline \multirow{3}{*}{ Run } & \multicolumn{7}{|c|}{ Operating Condition } \\
\cline { 2 - 8 } & \multirow{2}{*}{$\begin{array}{c}\text { Stage } \\
\text { amont }\end{array}$} & \multicolumn{2}{|c|}{$\begin{array}{c}\text { Temperature } \\
\left({ }^{\circ} \mathrm{C}\right)\end{array}$} & \multicolumn{2}{c|}{$\begin{array}{c}\text { Initial } \\
\text { pressure }\end{array}$} & \multicolumn{2}{c|}{$\begin{array}{c}\text { Time } \\
\text { (hour) }\end{array}$} \\
\cline { 3 - 9 } & T1 & T2 & P1 & P2 & t1 & t2 \\
\hline 1 & 1 & 300 & - & 30 & - & 1 & - \\
\hline 2 & 1 & 330 & - & 30 & - & 1 & - \\
\hline 3 & 1 & 360 & - & 30 & - & 1 & - \\
\hline 4 & 1 & 400 & - & 30 & - & 1 & - \\
\hline 5 & 1 & 300 & - & 60 & - & 1 & - \\
\hline 6 & 1 & 330 & - & 60 & - & 1 & - \\
\hline 7 & 1 & 360 & - & 60 & - & 1 & - \\
\hline 8 & 1 & 400 & - & 60 & - & 1 & - \\
\hline 9 & 2 & 300 & 300 & 30 & 30 & 1 & 1 \\
\hline 10 & 2 & 300 & 330 & 30 & 30 & 1 & 1 \\
\hline 11 & 2 & 300 & 360 & 30 & 30 & 1 & 1 \\
\hline 12 & 2 & 300 & 400 & 30 & 30 & 1 & 1 \\
\hline 13 & 1 & 300 & - & 60 & - & 4 & - \\
\hline 14 & 1 & 400 & - & 60 & - & 4 & - \\
\hline 15 & 1 & 300 & - & 30 & - & 4 & - \\
\hline 16 & 1 & 400 & - & 30 & - & 4 & - \\
\hline
\end{tabular}

\section{Discussion}

\subsection{Pressure and Temperature Profile}

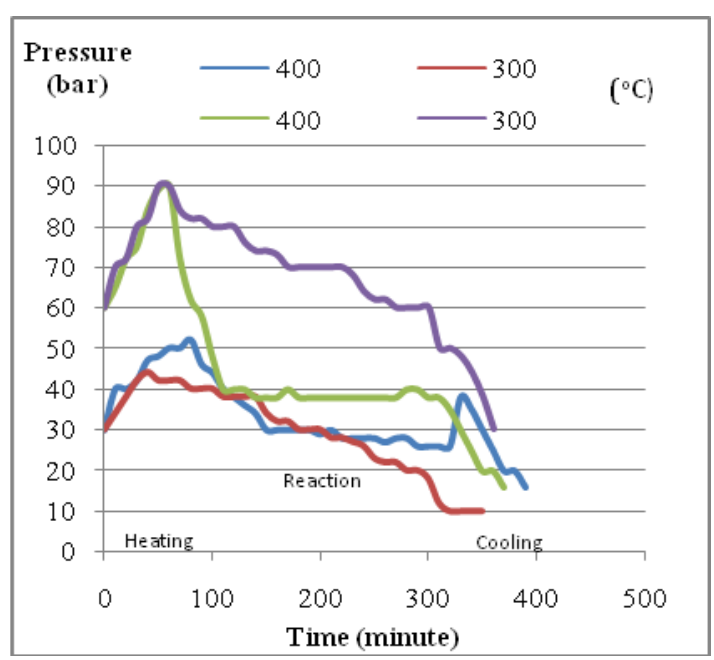

Fig. 4. Pressure profile on the time

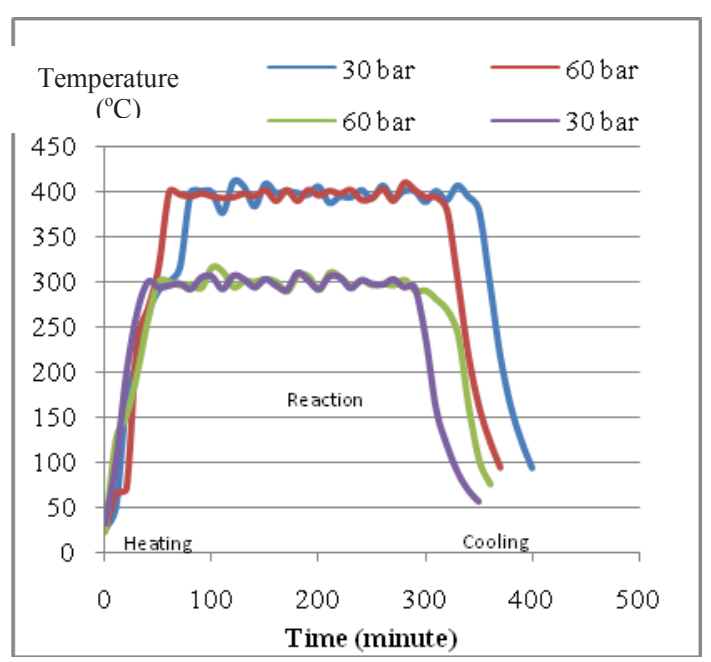

Fig. 5 Temperature Profile on The Time

The pressure and temperature profile of the above reaction was observed at 4 hours reaction time. By controlling the temperature of the coil heater in the reactor it was desirabled that the reaction temperature was immediately achieved and kept constant during the reaction. The observation of the condition of the process pressure was seen fluctuating even pressure drop on the graph above. This pressure drop phenomenon follows the Joule Thompson Effect theory. The hydrogen gas stored in a guarded tube at a pressure of about 200-250 bar to remain in the gas phase was then injected into the reactor at a pressure of 30 or 60 bar. As a result of this pressure drop, the gas became inflate and the rapid 
pressure drop was practically not allowing the occurrence of external heat propagation into the system and vice versa $(Q=0)$. As a result of this adiabatic development the gas underwent temperature changed both up and down (fluctuations).

\subsection{Effect of Temperature on Green Diesel Yield}

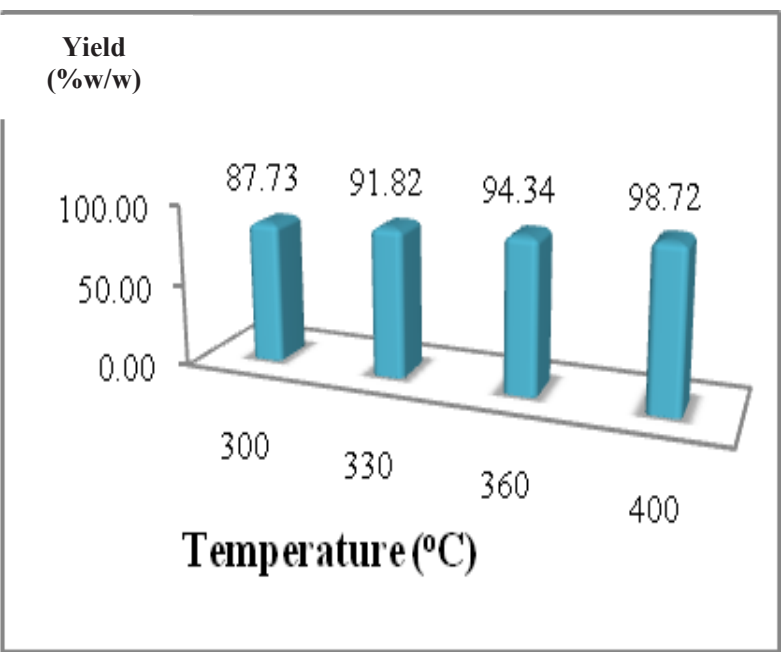

Fig. 6. Effect of Temperature on Green Diesel Yield

At the initial pressure condition of 30 bar and 1 hour reaction time, the highest result is obtained at $400^{\circ} \mathrm{C}$ operating temperature of $98.72 \%$ considering green diesel $\mathrm{C}_{13}-\mathrm{C}_{22}$. This is because when the temperature is increased then the cracking process will occur more easily and optimally. It is also caused by the addition of greater heat energy.

\subsection{Effect of Initial Pressure Reaction to Green Diesel Yield}

At $400^{\circ} \mathrm{C}$ and a reaction time of 1 hour, the green diesel produced at a pressure of 60 bar is lower than the pressure of 30 bar. It is predicted that at higher pressures the incorporation of alkyl in short carbon chains results in long-chain hydrocarbons $\mathrm{C} 23^{+}$which are not green diesel but it was a small part of the wax [15].

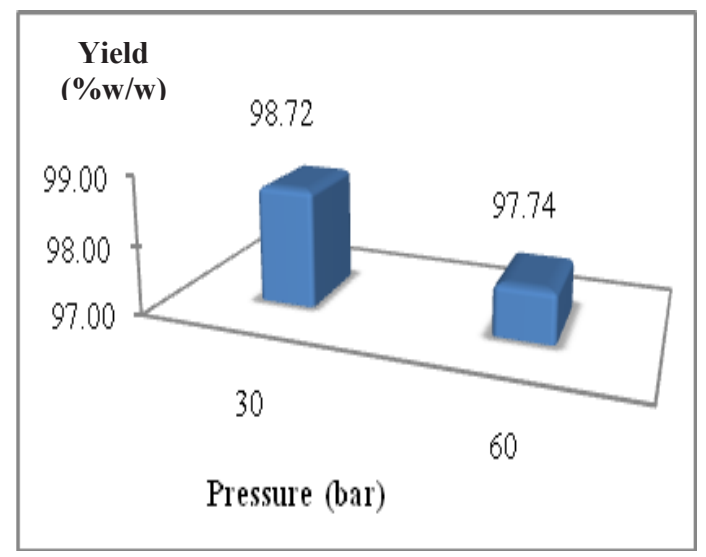

Fig. 7. Effect of Initial Pressure Reaction to Green Diesel Yield

\subsection{Effect of Reaction Time to Green Diesel Yield}

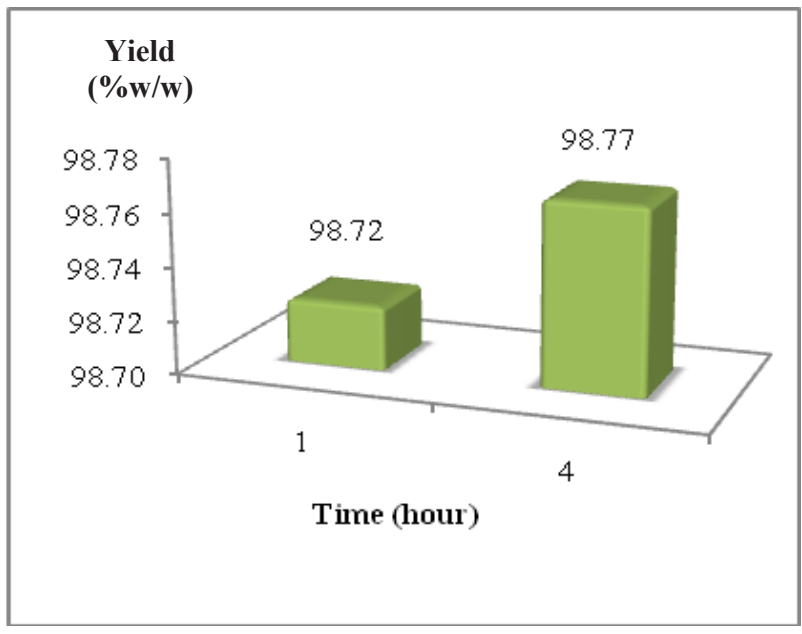

Fig. 8. Effect of Reaction Time on Green Diesel Yield

Results at 4 hours of operating time are higher than the operating time of 1 hour only. The longer the reaction time, the cracking process also occurs more optimally because the contact between reactants and catalysts longer to produce more products that also cause the green diesel increased.

\subsection{Effect of Number of Stages of Reaction to Green Diesel Yield}

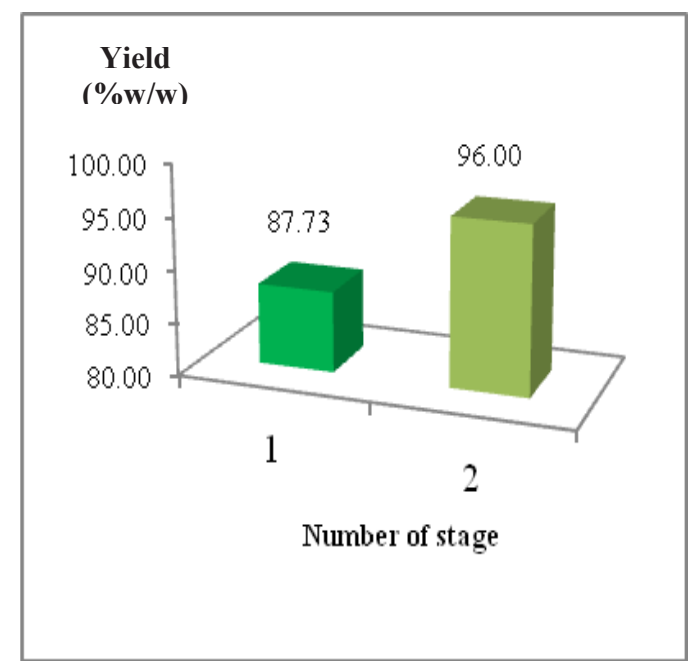

Fig. 9. Effect of Number of Stages of Reaction to Green Diesel Yield

Results at 2 stages are higher than the reaction result of only 1 stage. This is due to the cracking process at 2 stages occurs longer where every 1 stage is given 1 hour so that if 2 stage then happened 2 hour reaction of cracking. In addition, replacement with fresh hydrogen makes the cracking process more optimal. 


\subsection{Effect of Reaction Temperature on Decreasing Oxygen Content}

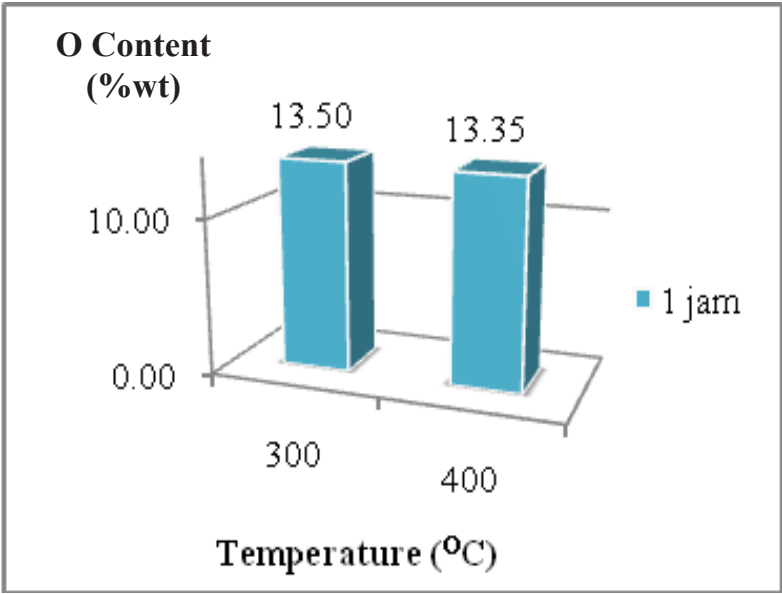

Fig. 10. Effect of Reaction Temperature on Decreasing Oxygen Content

In a reaction that lasted 1 hour, waste cooking oil which originally contained $14.25 \%$ oxygen can be reduced to 13.5 and $13.35 \%$ oxygen at reaction temperature of 300 and $400 \mathrm{oC}$ respectively. Although only less than $1 \%$ but with increasing reaction temperature, it is possible to remove oxygen contained in the fatty acid chain in waste cooking oil.

\section{Conclusion and Suggestion}

\subsection{Conclusion}

Based on the research that has been done, obtained some conclusions include:

1. The highest yield was obtained under operating conditions with 2 stage reaction, where $\mathrm{T}_{1}=$ $300{ }^{\circ} \mathrm{C}, \mathrm{T}_{2}=400{ }^{\circ} \mathrm{C}, \mathrm{P}_{1}=\mathrm{P}_{2}=30$ bar, $\mathrm{t}_{1}=\mathrm{t}_{2}=1$ hour that was equal to $98,93 \%$

2. Factors affecting green diesel yields were pressure, temperature, number of stages and time.

3. Oxygen levels decreased from $14.25 \%$ to $13.35 \%$ at $\mathrm{T}=400^{\circ} \mathrm{C}, \mathrm{P}_{1}=30$ bar, $\mathrm{t}=1$ hour.

\subsection{Suggestions}

Suggestions that can be submitted for further research include:

1. In order to improve the quality of green diesel product produced, it is necessary to learn more about the hydrodeoxigenation operation condition made from used cooking oil, especially operating pressure and operating temperature need to be increased.
2. Should be further studied related to raw material pretreatment method, product separation, catalyst used and product treatment before analyzed in order to obtain more optimal result.

3. Need further study related to isomerization reaction to get more comprehensive green diesel result.

4. Required product quality analysis such as GCMS, calorific value and FTIR, cetane number measure the success of research that has been done.

\section{Acknowledgments}

Financial support from Center of Technology Energy Resources and Chemical Industry - Agency for The Assessment and Applycation of Technology for this research are gratefully acknowledged.

\section{Reference}

[1] BPPT, Outlook Energi Indonesia 2015, Jakarta, 2015

[2] Dewajani H., Prosiding Seminar Nasional Energi Alternatif, Politeknik Negeri Malang, (2008)

[3] Dewajani H. dan Budiman A., Prosiding Seminar Nasional Technoin UII, Yogyakarta, (2012)

[4] He Z. Wang X., Catal Sustain Energy (1) 28$52(2012)$

[5] Chew T.L., Bathia S. Bioresour, Technol (03) 009 (2008)

[6] Hilten R., Speir R., Kastner J,. and Das K.C., Bioresour Technol (102) 8288 - 8294 (1992)

[7] Idem R.O., Katikaneni S.P.R., and Bakhshi N.N. ,Energy \& Fuels, 10 (6) 1150 - 1162 (1996)

[8] Ketaren S.D.G., Soares V.C.D., Ribeiro E.B., Carvalho D.A., Cardoso E.C.V., Rassi F.C., Mundim K., Rubim J.C., and Suarez P.A.Z., Jounal Anal. Appl.Pyrolysis (71) 987 - 996 (2004)

[9] Maher K.D., and Bressler D.C., Bioresour Technol (98) 2351-2368 (2007)

[10] Ma F., and Hanna M.A., Bioresour Technol (70) 1-15 (1999)

[11] Naveenji Arun, Rajesh V. Sharma Ajay K. Dalai, Renewable and sustainable energy (48) 240-255 (2015)

[12] Bendenzu S. Cid. R., Fierro J.L.G., and Agudo L., Appl.Catal. A: General (197) 47- 
$60(2000)$

[13] Mohammad M., Kandaramath T., Yaakob Z., Chandra Y., Energy Rev (22) 121-132 (2013)

[14] Perego Carlo, Biomass to Advanced Biofuel, (2015)

[15] Barton D.G., Soled S.L., and Iglesia E., Topics in Catalysis (6) 87 - 99 (1998) 